\title{
Plasma fibronectin is a component of cryoglobulins from patients with connective tissue and other diseases
}

\author{
BYRON ANDERSON, ${ }^{1}$ MEGAN RUCKER, ${ }^{2}$ RUTH ENTWISTLE, ${ }^{3}$ \\ FRANK R. SCHMID, ${ }^{4}$ AND GARY W. WOOD ${ }^{2}$
}

From the Departments of Biochemistry, Otolaryngology and Maxillofacial Surgery, and Medicine, Northwestern University Medical and Dental Schools, Chicago, Illinois 60611; and the Department of Pathology, University of Kansas Medical Center, Kansas City, Kansas 66103, USA

SUMMARY Twenty-four washed cryoglobulin precipitates were examined for the presence of plasma fibronectin, immunoglobulins, complement components $\mathrm{Clq}$ and $\mathrm{C} 3$, and fibrinogen. Plasma fibronectin was detected in all preparations by immunodiffusion with antifibronectin serum, whereas the other components were found in some but not all of the cryoglobulins.

Cryoglobulins occur with an incidence of approximately $6 \%$ in individuals with haematopoietic malignancies, connective tissue diseases, and chronic or acute infections. ${ }^{1}$ The cryoglobulinaemias are classified into 3 groups: those containing monoclonal immunoglobulins (Igs), mixed cryoglobulins containing monoclonal Ig with antibody activity to polyclonal immunoglobulin $\mathrm{G}$ (IgG), and the polyclonal cryoglobulins containing 1 or more classes of Ig. ${ }^{2}$ The latter 2 types of cryoglobulins may contain rheumatoid factor activities, other autoantibody reactivities, complement components, and antigens reactive with the corresponding autoantibody. ${ }^{3-6}$

Possible factors responsible for the insolubility in the cold of monoclonal cryoimmunoglobulins (cryo-Igs) have recently been discerned by Middaugh et $a{ }^{7}{ }^{7}$ They showed that the tertiary structure of cryo-Igs differs from soluble Igs and that the low temperature insolubility of cryo-Igs may be an intrinsic property of the structure which favours associations between cryo-Ig molecules. Although many factors have been studied which affect the Accepted for publication 25 January 1980

${ }^{1}$ Departments of Biochemistry and Otolaryngology and Maxillofacial Surgery, Northwestern U. Medical and Dental Schools. Chicago, Illinois 60611.

${ }^{2}$ Department of Pathology, University of Kansas Medical Center, Kansas City, Kansas 66103.

${ }^{3}$ Department of Biochemistry, Northwestern University Medical School, Chicago, Illinois 60611.

${ }_{4}^{4}$ Section of Arthritis-Connective Tissue Diseases, Department of Medicine, Northwestern University Medical School, Chicago, Illinois 60611.

Correspondence to Dr Byron Anderson, Department of Biochemistry, Northwcstern University Medical School, Chicago, Illinois 60611, USA. solubility of the polyclonal cryoglobulins, ${ }^{8}$ there is no evidence to suggest that Igs of the cold-insoluble polyclonal type differ in structure from coldsoluble Igs.

We report here that plasma fibronectin (PFN is a component of all the cryoglobulins tested Fibronectin (FN) is a normal plasma constituen whose physical-chemical properties have been extensively studied. ${ }^{910}$ The molecule has a large molecular weight (440000 daltons), probably consists of 2 identical subunits, and contains a small percentage of carbohydrate. FN is also a major constituent of the cell surface components of fibroblastic and endothelial cells, and the cell surface FN differs from PFN by being larger by approximately 10000 daltons. Viral transformation of tissue cultured cell lines usually results in the loss of FN expression on the cell surface. Several biological activities have been suggested for the FN molecule, including mediating cell-cell and cell-substratum adhesiveness and the function of removal of colloids by liver cells and macrophages. PFN has also been shown to have binding properties to several other molecules, including fibrin-fibrinogen collagen, and heparin..$^{11-13}$ The possibility that the PFN found in the cryoglobulins may be binding to some component of the cryo-Igs and involved in the cryoprecipitation phenomenon is discussed.

\section{Materials and methods}

PATIENTS

The cryoglobulins from 24 patients were studied. Six of the patients were diagnosed as having systemic lupus erythematosus (SLE), 2 rheumatoid 
arthritis (RA), 1 polyarthritis, 4 essential mixed cryoglobulinaemia, and 1 Waldenström's macroglobulinaemia. Two patients were being seen for chronic infections, 1 identified as lichen myxoedematosis and 1 cytomegalovirus. Eight of the patients had different types of clinical features, the primary disorder not being known. They included: 3 with haemolytic anaemia and thrombocytopenia and 1 each with thrombophlebitis, chronic urticaria, cardiovascular arrest, renal disease, and platelet satellite phenomenon.

\section{SERA COLLECTION AND CRYOGLOBULIN}

\section{PREPARATION AND ANALYSES}

Blood was collected into prewarmed tubes and allowed to clot at $37^{\circ} \mathrm{C}$. The clot was removed by centrifugation at $1600 \mathrm{~g}$ for 30 minutes and the serum placed at $4^{\circ} \mathrm{C}$ for $24-48$ hours. Precipitated material was collected by centrifugation at $1600 \mathrm{~g}$ for 20 minutes and $4^{\circ} \mathrm{C}$, and the cryoglobulin precipitates were washed twice with phosphate buffered saline (PBS), pH 7·2. The cryoglobulins were dissolved by warming the cryoglobulin precipitates to $37^{\circ} \mathrm{C}$ or $56^{\circ} \mathrm{C}$ in PBS. When the collected cryoglobulins were kept at $4^{\circ} \mathrm{C}$ for more than a few days, they became relatively more difficult to solubilise by warming. Several of these were dissolved by warming to $37^{\circ} \mathrm{C}$ in the PBS containing $1 \mathrm{M}$ urea. If $37^{\circ} \mathrm{C}$ or $56^{\circ} \mathrm{C}$ was sufficient to dissolve most of the cryoglobulin, the urea solution was not used. The protein concentrations of the solubilised portions as determined by the optical density ratios at 280 and $260 \mathrm{~nm}$ varied between 0.045 and 1.7 $\mathrm{mg} / \mathrm{ml}$. IgG, IgM. IgA, Clq, C3, and fibrinogen were analysed by double immunodiffusion in agarose plates (Behring) with monospecific antisera to the human substances (Cappel Laboratories).

\section{PREPARATION OF PLASMA FIBRONECTIN}

AND ANTIPLASMA FIBRONECTIN SERA

Plasma fibronectin (PFN) was purified by a modification of the procedure of Engvall and Ruoslahti. ${ }^{12}$ Gelatin ( $8 \mathrm{~g}$, Sigma Chemical Co.) was dissolved in a mixture of $60 \mathrm{ml}$ of PBS and $10 \mathrm{ml}$ of $1 \mathrm{M}$ sodium acetate, $\mathrm{pH} 5 \cdot 0$, and $4 \mathrm{ml}$ of $25 \%$ glutaraldehyde was immediately added dropwise. The reaction mixture was stirred at room temperature overnight. The insolubilised gelatin was placed in a $2 \times 60 \mathrm{~cm}$ column, and the gelatin was washed with $1 \%$ Triton $\mathrm{X}-100$ in PBS, $3 \mathrm{M} \mathrm{KC1}, 1 \mathrm{M}$ urea in PBS, and $8 \mathrm{M}$ urea in PBS. Plasma $(500 \mathrm{ml})$ was passed through the column and the gelatin washed with 2 column volumes each of PBS, $1 \%$ Triton $\mathrm{X}-100$ in PBS, $3 \mathrm{M} \mathrm{KC1}$, and $1 \mathrm{M}$ urea in PBS. PFN was eluted with $8 \mathrm{M}$ urea in PBS. The eluate was concentrated with a filter cone (Amicon Corporation) and dialysed against $0.5 \mathrm{M}$ urea in PBS at $4^{\circ}$ for 24 hours. The precipitate was collected by centrifugation and dissolved by warming in $0.5 \mathrm{M}$ urea in PBS. PFN was also obtained as a gift from Dr Isaac Cohen, Northwestern University Medical School. The PFN preparations showed no reactivity in double immunodiffusion with antisera to human Igs, complement, or clotting components.

Antisera were prepared to PFN by multiple site injections (subcutaneous, intramuscular, interperitoneal) of rabbits with $100-200 \mu \mathrm{g}$ of PFN emulsified in complete Freund's adjuvant (Miles Laboratories). Subsequent immunisations were done biweekly with the same amounts of PFN in incomplete Freund's adjuvant.

Serum was obtained 7-10 days after each immunisation, and by 8 weeks strong precipitin lines were seen in double immunodiffusion of the antisera against purified PFN and human plasma. A single precipitin band was obtained with the latter 2 antigen sources with no additional precipitin formation or spurring. The anti-PFN sera showed no reactivity to purified human Igs, complement, or clotting components. The commercial antisera to the latter components showed no indications of cross-reactions with the line formed by anti-PFN sera, and plasma or purified PFN.

Quantitations of PFN were done by a method similar to that published by Ruoslahti et al. ${ }^{14}$ PFN $(10 \mu \mathrm{g})$ was radiolabelled with $2 \mathrm{mCi}$ of $\mathrm{Na}^{125} \mathrm{I}$ (Amersham Corporation) plus $0.04 \mathrm{mg}$ of chloramine-T for 1 minute at $23^{\circ} \mathrm{C}$. The reaction was stopped by the addition of $0.03 \mathrm{mg}$ sodium metabisulphite. KI $(0 \cdot 1$ of a $0 \cdot 1 \mathrm{~N}$ Solution) and PBS containing $0.1 \%$ bovine serum albumin (BSA) were also added to the reaction mixture, and the ${ }^{125}$ I-PFN and free ${ }^{125}$ I separated on a Sephadex G-25 column. The ${ }^{125}$ I-PFN was further purified by adsorption to glutaraldehyde-insolubilised gelatin by incubation with the gelatin for 1 hour at $23^{\circ} \mathrm{C}$. The gelatin was washed extensively with PBS and ${ }^{125}$ I-PFN removed with $4 \mathrm{M}$ urea in PBS containing $1 \%$ BSA. $80 \%$ of the purified ${ }^{125}$ I-PFN bound to antibody in the radioimmunoassay (RIA). The second antibody (goat anti-rabbit IgG serum. Miles Laboratories) was absorbed by incubation of $2 \mathrm{ml}$ of the antiserum with $1 \mathrm{ml}$ of glutaraldehyde-insolubilised gelatin. The RIA reaction mixtures consisted of $15 \mu \mathrm{l}$ of ${ }^{125}$ I-PFN (specific activity approximately 80000 $\mathrm{cpm} / \mathrm{ng}$ ), and anti-PFN serum diluted to titre in 1:100 diluted normal rabbit serum $(300 \mu \mathrm{l})$ in PBS containing $1 \% \mathrm{BSA}$. After incubation at $37^{\circ} \mathrm{C}$ for 2 hours $40 \mu \mathrm{l}$ of the absorbed second antibody was added, and incubation was continued for 1 hour at $37^{\circ} \mathrm{C}$. The precipitates were removed by centrifugation at $1500 \mathrm{xg}$ for 45 minutes and counted in a 
gamma counter. Known amounts of purified PFN were added to construct an inhibition curve, and varying amounts of dissolved cryoglobulins were quantitated for PFN concentration.

\section{Results}

The cryoglobulins in this study were defined as the portion of sera drawn and clotted at $37^{\circ} \mathrm{C}$ which precipitated at $4^{\circ} \mathrm{C}$ for 24 to 48 hours. The precipitated fractions showed differences in solubility, some readily dissolving on warming to $37^{\circ} \mathrm{C}$ and others leaving small amounts of precipitate on warming to $56^{\circ} \mathrm{C}$ or $37^{\circ} \mathrm{C}$ in $1 \mathrm{M}$ urea-PBS. Only the soluble portions were examined for their components. As shown in Table 1, all of the PBS washed and dissolved fractions of the cryoglobulins contained a component which was reactive with antisera prepared to PFN. In addition, 17 of the 20 cryoglobulins tested for IgG contained that component. The cryoglobulin derived from the patient with Waldenström's macroglobulinaemia was positive for IgM but not IgG or IgA. Several other cryo-

Table 1 Components detected in washed cryoglobulin precipitates*

\begin{tabular}{lllllllll}
\hline $\begin{array}{l}\text { Cryo- } \\
\text { globulin }\end{array}$ & PFN & IgG & IgM & IgA & Clq & C3 & $\begin{array}{c}\text { Fibri- } \\
\text { nogen }\end{array}$ & $\begin{array}{l}\text { Diag- } \\
\text { nosest }\end{array}$ \\
\hline $\mathbf{1}$ & + & - & - & - & - & - & + & RA \\
$\mathbf{2}$ & + & + & + & + & - & + & - & RA \\
$\mathbf{3}$ & + & + & + & + & - & - & - & PA \\
$\mathbf{4}$ & + & - & - & - & ND & + & - & SLE \\
$\mathbf{5}$ & + & + & - & - & - & - & - & SLE \\
$\mathbf{6}$ & + & + & - & - & - & - & - & SLE \\
$\mathbf{7}$ & + & + & - & - & - & - & - & SLE \\
$\mathbf{8}$ & + & ND & ND & ND & - & ND & - & SLE \\
$\mathbf{9}$ & + & ND & ND & ND & ND & ND & - & SLE \\
$\mathbf{1 0}$ & + & - & + & - & - & ND & - & WM \\
$\mathbf{1 1}$ & + & + & + & + & - & - & - & EMC \\
$\mathbf{1 2}$ & + & + & + & - & + & - & - & EMC \\
$\mathbf{1 3}$ & + & + & + & - & - & - & - & EMC \\
$\mathbf{1 4}$ & + & + & + & - & - & - & - & EMC \\
$\mathbf{1 5}$ & + & + & + & - & - & - & - & CU \\
$\mathbf{1 6}$ & + & + & + & + & ND & + & - & HA, TCP \\
$\mathbf{1 7}$ & + & + & + & ND & - & ND & - & HA, TCP \\
$\mathbf{1 8}$ & + & + & ND & ND & ND & + & - & HA, TCP \\
$\mathbf{1 9}$ & + & ND & + & ND & ND & ND & - & CMV \\
$\mathbf{2 0}$ & + & + & + & + & - & + & - & TP \\
$\mathbf{2 1}$ & + & + & + & + & + & + & - & CVA \\
$\mathbf{2 2}$ & + & + & + & + & + & + & - & PSP \\
$\mathbf{2 3}$ & + & + & ND & ND & - & + & - & RD \\
$\mathbf{2 4}$ & + & ND & ND & ND & ND & ND & - & LM \\
\hline
\end{tabular}

${ }^{*}$ Blood specimens were collected and clotted at $37^{\circ} \mathrm{C}$ and the sera placed at $4^{\circ} \mathrm{C}$ for 24 or 48 hours. The cryoglobulins were collected by centrifugation and washed 3 times at $4^{\circ} \mathrm{C}$ with PBS. The precipitates were then redissolved and tested for the various components listed by double immunodiffusion analyses. $+=$ positive as defined by precipitin band formation, $-=$ negative; ND $=$ not determined.

$\dagger$ Abbreviations for diagnoses: RA, rheumatoid arthritis; PA, polyarthritis; SLE, systemic lupus erythematosis; WM, Waldenström's macroglobulinaemia; EMC, essential mixed cryoglobulinaemia; CU, chronic urticaria; HA, TCP, haemolytic anaemia and thrombocytopenia; CMV, cytomegalovirus; TP, thrombophlebitis; CVA, cardiovascular arrest; PSP, platelet satellite phenomenon; RD, renal disease; LM, lichen myxoedematosis. globulins contained either IgM or IgA or both. C1q and C3 were detected in 2 and 8 , respectively, of the cryoglobulins. Fibrinogen was detected in only 1 of all the dissolved cryoglobulin fractions. The components negative by double immunodiffusion may be present but below the limits of detection of that method. As shown in Fig. 1, antiPFN serum formed single-precipitin bands with solubilised cryoglobulins which fused with the precipitin band formed with purified PFN and plasma and serum.

Several experiments were done to ascertain whether PFN was loosely adherent to other components of the cryoglobulin. Several cryoglobulin precipitates were solubilised by warming and reprecipitated at $4^{\circ}$ repeatedly and an aliquot removed at each solubilisation stage. All of the solubilised portions were positive by precipitin band formation in double immunodiffusion against anti-PFN serum. Moreover, extensive washing of cryoglobulin precipitates at $4^{\circ} \mathrm{C}$ with PBS did not remove the PFN.

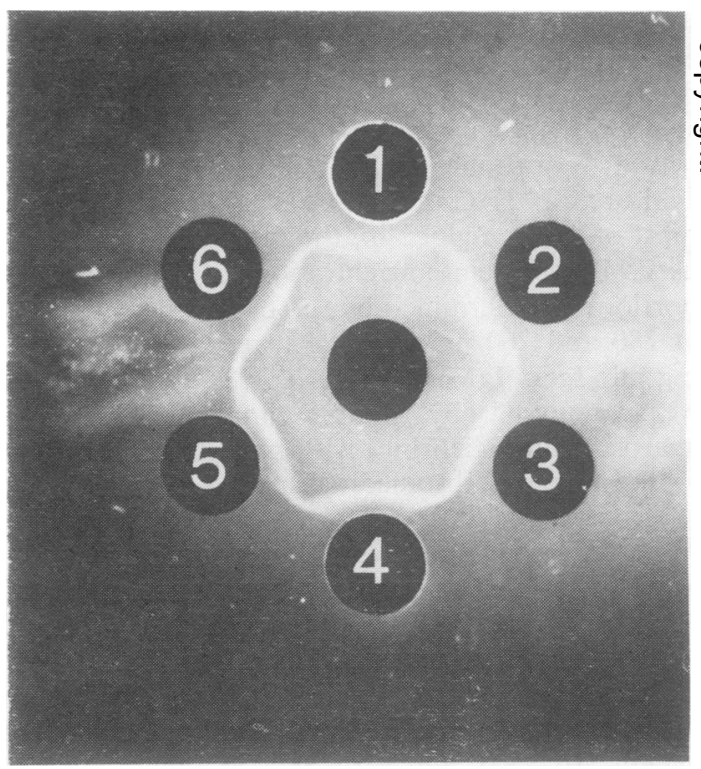

Fig. 1 Double immunodiffusion analysis of solubilised cryoglobulin fractions against antiplasma fibronectin serum. Wells 1 and 2 contained the solubilised cryoglobulins of 2 different individuals with essential mixed cryoglobulinaemia; wells 3 and 6 contained purified PFN; well 4, 1:2 diluted normal human serum; well 5, $1: 3$ diluted normal human plasma; the centre well contained anti-PFN serum. A single precipitin band formed with all antigen sources which fused without apparent spurring. The appearance of a spur-like precipitin with the human serum and plasma antigens is due to a prozone effect near those wells. 
Table 2 Percentages of ${ }^{125}$ I-labelled PFN added to serum precipitating with cryoglobulins and of PFN assayed in the cryoglobulin fractions by RIA

\begin{tabular}{|c|c|c|c|}
\hline & & $\begin{array}{l}\text { Per cent of total PFN } \\
125 I-P F N^{*}\end{array}$ & $N_{\text {PFN† }}$ \\
\hline $\begin{array}{l}3 . \\
4 . \\
5 .\end{array}$ & 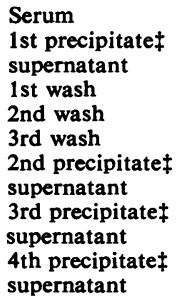 & $\begin{array}{r}100 \\
7 \cdot 5 \\
90 \cdot 2 \\
2 \cdot 1 \\
0 \cdot 1 \\
0 \cdot 1 \\
3 \cdot 9 \\
3 \cdot 7 \\
3 \cdot 0 \\
1 \cdot 2\end{array}$ & $\begin{array}{l}100 \\
9 \cdot 4 \\
89 \\
1 \cdot 3 \\
0 \cdot 3 \\
0 \cdot 2 \\
7 \cdot 1 \\
2 \cdot 6 \\
6 \cdot 9 \\
0 \cdot 1 \\
6 \cdot 6 \\
0.2\end{array}$ \\
\hline
\end{tabular}

*A total of $2.7 \times 10^{5} \mathrm{cpm}$ of $125 \mathrm{I}-\mathrm{PFN}\left(7.2 \times 10^{4} \mathrm{cpm} / \mathrm{ng}\right)$ were added to the $1 \mathrm{ml}$ of serum.

†Serum (14 ml) was treated in the same manner as the serum to which the 125I-PFN was added and the various fractions assayed by RIA for PFN as described in the text.

$\ddagger$ The 1st precipitate was collected by centrifugation after the serum remained at $4^{\circ} \mathrm{C}$ for 48 hours and was washed 3 times with PBS (1st, 2nd, and 3rd washes). The 2nd, 3rd, and 4th precipitates were those obtained after redissolving the preceding precipitate in PBS at $37^{\circ} \mathrm{C}$ and reprecipitation at $4^{\circ} \mathrm{C}$ for 24 hours.

In one experiment (Table 2) ${ }^{125}$ I-PFN was added to the freshly drawn serum from a patient with essential mixed cryoglobulinaemia and the ${ }^{125}$ I-PFN followed through stages of precipitation, solubilisation, and reprecipitation. As seen in the Table, $7 \cdot 7 \%$ of the total ${ }^{125} \mathrm{I}-\mathrm{PFN}$ remained in the cryoprecipitated fraction of serum.

If it is assumed that the original concentration of PFN in the serum was $150 \mu \mathrm{g} / \mathrm{ml}$ the precipitate would contain approximately $12 \mu \mathrm{g}$ of PFN. The second and third PBS washes of the precipitate contained negligible counts, again showing that the PFN probably was not loosely adherent to other cryoglobulin components. When the redissolved first precipitate was allowed to precipitate in the cold, approximately $50 \%$ of the ${ }^{125}$ I-PFN reprecipitated, and approximately $70 \%$ of the latter reprecipitated a third time. Thus, the PFN becomes insoluble in the cold with other cryoglobulin components after removal of other serum factors and solubilisation.

In a separate experiment a different serum was processed in the same manner and the PFN in the various fractions was quantitated by RIA. As can be seen in Table 2, results were obtained which were similar to those as in the experiment where ${ }^{125} \mathrm{I}$ PFN was added to serum. These results confirmed the observations that a fraction of PFN coprecipitated in the cold with the other components of cryoglobulins and that the PFN was reprecipitable in several cycles of precipitation-solubilisation.

\section{Discussion}

Cryoglobulins may consist of many components. In individuals with autoantibodies the cryoglobulins can include IgG or IgM with the autoantibody specificity; $\operatorname{IgA}$ and various complement components are also detectable. ${ }^{4-615}$ We report here that PFN was also a component of all the cryoglobulins tested, most of which were apparently of the polyclonal type. We have not tested monoclonal cryo-Igs nor have we directly ascertained whether a rheumatoid factor active cryo-Ig precipitate with IgG contains PFN. It is possible that either of the 2 cryoglobulins from patients with RA reported here may have contained rheumatoid factor activity. Because PFN associates with many other proteins, including fibrin and collagen, ${ }^{13}$ it is pertinent to ask to which component of the cryoglobulins PFN is binding. A portion may be binding to $\mathrm{Clq}$ as $\mathrm{Clq}$ contains collagen-like segments. Moreover, we have noted that some IgG copurifies with PFN in certain stages of the glutaraldehyde-polymerised gelatin method (unpublished observations); thus PFN may associate to some extent with Igs or a fraction of Igs. Alternatively, PFN, which is defined as a cold-insoluble globulin, may simply coprecipitate at $4^{\circ} \mathrm{C}$ with other components of cryoglobulins. However, it has been shown that the cell surface form of purified FN is fractionally soluble at neutral $\mathrm{pH}$ and $0^{\circ} \mathrm{C}$ at a concentration of $0.5 \mathrm{mg} / \mathrm{ml} .^{16}$ Further, the purified PFN used in these studies remained soluble in PBS at concentrations of 0.2 $0.8 \mathrm{mg} / \mathrm{ml}$ over extended periods of time at $4^{\circ} \mathrm{C}$. Therefore it would be expected that in the repeated precipitation-solubilisation experiments PFN would be removed from the cryoglobulin precipitates.

It will be of interest to determine to what component(s) of the cryoglobulins PFN is associated and also to ascertain if the presence of PFN affects the cryoprecipitability of cryoglobulins. These questions are being investigated.

These studies were supported by National Institutes of Health grants AM-16326 and CA-19333, and by a grant from the Illinois Chapter of the Arthritis Foundation. B. A. is the recipient of Research Career Development Award number AM-70787.

\section{References}

1 Grey H M, Kohler P F. Cryoimmunoglobulins. Semin Hematol 1973; 10: 87-112.

2 Brouet J-C, Clauvel J-P, Danon F, Klain M, Seligmann M. Biologic and clinical significance of cryoglobulins. A report of 86 cases. Am J Med 1974; 57: 775-88.

3 Meltzer M, Franklin E C, Elias K, McCluskey R T, Cooper N. Cryoglobulinemia-a clinical and laboratory study. II. Cryoglobulins with rheumatoid factor activity. Am J Med 1966; 40: 837-56. 
4 Wilson M R, Arroyave C M, Miles L, Tan E M. Immune reactants in cryoproteins. Relationship to complement activation. Ann Rheum Dis 1977; 36: 540-8.

5 Kodama D. Determination of cryoglobulins as lipoprotein-autoantibody immune complexes and antigenic determinants against anti-lipoprotein autoantibody. Clin Exp Immunol 1977; 28 : 437-44.

6 Roberts J L, Lewis E J. Identification of antinative DNA antibodies in cryoglobulinemic states. Am J Med 1978; 65: 437-45.

7 Middaugh C R, Gerber-Jensen B, Hurvitz A, Paluszek A, Scheffel C, Litman G W. Physicochemical characterization of six monoclonal cryoimmunoglobulins. Possible basis for cold-dependent insolubility. Proc Natl Acad Sci USA 1978; 75: 3440-44.

8 Meltzer M, Franklin E C. Cryoglobulinemia-A study of twenty-nine patients. I. IgG and IgM cryoglobulins and factors affecting cryoprecipitability. Am J Med 1966; 40: 828-56.

- Vaheri A, Mosher D F. High molecular weight, cell surface-associated glycoprotein (fibronectin) lost in malignant transformation. Biochim Biophys Acta 1978; 516: $1-25$.
10 Yamada K M, Olden K. Fibronectins-adhesive glycoproteins of cell surface and blood. Nature 1978; 275: 179-184.

11 Stathakis N E, Mosesson M W. Interactions among heparin, cold-insoluble globulin, and fibrinogen in formation of the heparin precipitable fraction of plasma. $J$ Clin Invest 1977; 60: 855-65.

12 Engvall E, Ruoslathi E. Binding of soluble form of fibroblast surface protein, fibronectin, to collagen. Int $J$ Cancer 1977; 20: 1-5.

13 Engvall E, Rouslahti E, Miller E J. Affinity of fibronectin to collagens of different genetic types and to fibrinogen. J Exp Med 1978; 147: 1584-95.

14 Ruoslahti $\mathrm{E}$, Vuento $\mathrm{M}$, Engvall $\mathrm{E}$. Interaction of fibronectin with antibodies and collagen in radioimmunoassay. Biochim Biophys Acta 1978; 534: 210-8.

15 Barnett E V, Bluestone R, Cracchiolo A, Goldberg L S, Kantor G L, McIntosh R M. Cryoglobulinemia and disease. Ann Intern Med 1970; 73: 95-107.

16 Yamada K M, Schlesinger D H, Kennedy D W, Pastan I. Characterization of a major cell surface glycoprotein. Biochemistry 1977; 16: 5552-9. 